\title{
THE EFFECTS OF NUCLEOTYPE AND GENOTYPE UPON POLLEN GRAIN DEVELOPMENT IN HYACINTH AND SCILLA
}

\author{
ANGELA KARP, H. REES and A. W. JEWELL \\ Department of Agricultural Botany, University College of Wales, Aberystwyth, U.K. \\ Received 23.x.81
}

\section{SUMMARY}

In pollen grains within anthers of a triploid Hyacinthus orientalis the average duration of the mitotic cycle and the average size of pollen grains are directly proportional to the nuclear DNA amount. The average length of chromosomes at metaphase of the first pollen grain mitosis decreases with increasing nuclear DNA amount. These findings confirm the control imposed by the nucleotype on the cell phenotype.

In pollen grain: of a triploid Scilla sibirica, a species less tolerant of aneuploidy than Hyacinthus orientalis, the evidence indicates that nucleotypic effects are, to a large degree, confounded by genic effects. Genic imbalance in aneuploid grains impedes their progress through the mitotic cycle. To generalise, we conclude that the nucleotype imposes constraints upon the mitotic cycle and other aspects of the cell phenotype but that the constraints may be confounded by modifications superimposed by interaction with genic effects.

\section{INTRODUCTION}

BENNETT (1972) distinguishes between two kinds of control exercised by the nucleus over cell growth and differentiation. The first, attributable to the genotype, is by the transcription and translation of information embodied within specific DNA base sequences. The second is independent of this information and attributable to what he calls the nucleotype whose properties relate to certain gross physical characteristics of the nucleus, its mass and, in particular, the amount of DNA in its constituent chromosomes. Familiar examples of the kind of control which is exercised by the nucleotype are the increase in the duration of mitotic cycles and the increase in cell volume consequent upon increase in nuclear DNA content, a subject reviewed at length by Cavalier-Smith (1978). While such effects are widespread and well established they are, in many ways, puzzling. Consider, for example, the well known fact that cell volume in root meristems of different higher plant species is directly correlated with nuclear DNA amount (Martin, 1966). The puzzle is that in different tissues of the same plant the cell volumes vary enormously and quite independently of the nuclear DNA amount. Clearly there is control of cell size over and above that exerted by the nucleotype. One assumes that both genic and nucleotypic factors must, normally, act and often interact with one another to control the cell volumes and, for that matter, many aspects of the cell phenotype. A particularly convenient opportunity for investigating such action and interaction is to be found in anthers during pollen grain development and, in particular, the development of pollen grains in triploid organisms. Following irregular chromosome segregation at meiosis in triploid pollen mother cells the DNA amounts in the nuclei of tetrads range from the haploid to 
the diploid. They cover therefore, a varied spectrum of nucleotypes. At the same time, however, the variation in DNA amount is accompanied by variation in nuclear genotype $i . e$., by a variety in the number and combination of genes located in the different chromosomes. The effects both of genotype and of nucleotype, and of their interactions, have been investigated in two triploid angio-sperms, the variety Jan Bos of hyacinth (Hyacinthus orientalis, $2 n=3 x=24$ ) and the variety Spring Beauty of the Siberian squill ( Scilla sibirica, $2 n=3 x=18$ ).

The characters investigated were (a), the timing sequence of pollen grains reaching metaphase of the first pollen grain mitosis, (b) the size of pollen grains and (c), the chromosome length in pollen grains. (b) and (c) were both measured at metaphase of the first pollen grain mitosis. The questions asked were, to what extent are (a), (b) and (c) determined by the nuclear DNA amount of individual pollen grains? To what extent are (a), (b) and (c) independent of the nuclear DNA amount?

\section{Methods}

\section{(i) Pollen grain mitosis}

Buds were fixed in Carnoy's solution and the chromosomes stained in aceto-carmine. Chromosome lengths and chromatid width at metaphase were measured from enlarged photographs.

\section{(ii) Pollen grain size}

The pollen grains in both species are roughly oval in outline. The area of each grain was consequently estimated at metaphase from the product of the lengths of the long and short axes $x \pi / 4$. Areas were more appropriate estimates of size than volumes because the grains were measured in squash preparations in which the grains tend to be flattened.

\section{(iii) The pollen grain index (P.G.I.)}

From buds at various stages of maturity a random sample of about 500 pollen grains per anther was classified into those with one nucleus $(O N)$, those with two $(T N)$ and those undergoing division. $O N$ represents grains at a developmental stage preceding mitosis, $T N$ grains which have undergone mitosis. A pollen grain index of the developmental "age" of each anther was derived from the formula $(100-\% O N+\% T N) / 2$. The P.G.I. ranges from 0 in young anthers to, theoretically, 100 in older anthers. Chromosome counts were made from samples of roughly equal numbers of grains in anthers covering the entire P.G.I. range in each species. With this information it is possible to determine whether grains with different chromosome numbers reach metaphase at different stages of anther development, i.e., at different P.G.I.'s.

\section{(iv) Conversion of P.G.I. to days}

In hyacinth we were able to convert P.G.I. values to days subsequent to the termination of meiosis. The procedure is based essentially on the method of Bennett (1970) for timing meiosis. Bulbs were pared down to 
leave only the base and the flower buds with protective leaf sheaths. These cores were kept in tubes with the base resting on water. A single anther at the end of meiosis $i . e$. , the second anaphase/tetrad stage was identified. (Anthers within one bud are closely synchronised.) Anthers from the same bud were sampled on subsequent days. By using buds from many cores grown in sequence it was possible to estimate the time taken for anthers to proceed from meiosis to the completion of pollen grain mitosis (i.e., P.G.I. 100). The information is given in fig. 1.

\section{(v) DNA amounts of individual pollen grains in hyacinth}

The haploid complement of hyacinth consists of four long $(L)$ chromosomes, two medium $(M)$ and two short $(S)$ chromosomes. The $2 C$ DNA content is 49.7 picograms. The DNA content of individual $L, M$ and $S$ chromosomes are proportional to their lengths, namely 8.9, 4.4 and 2.7 picograms respectively. With this information it is an easy matter to estimate the DNA amount for any grain given the number and distribution of $L$, $M$ and $S$ chromosomes.

\section{Results}

\section{Hyacinthus}

(i) Cell cycle

The distribution of chromosome numbers in pollen grains at metaphase at different timing indices are presented in table 1 . Fig. 1 plots the average

TABLE 1

The distribution at metaphase of pollen grains in triploid hyacinth with different chromosome numbers at different stages of anther development. Metaphase data are from counts in 1881 grains P.G.I. values from about 10,000 grains

\begin{tabular}{|c|c|c|c|c|c|c|c|c|c|c|c|}
\hline \multirow{2}{*}{$\begin{array}{l}\text { P.G.I. } \\
\text { range }\end{array}$} & \multirow{2}{*}{$\begin{array}{c}\text { Average } \\
\text { P.G.I. }\end{array}$} & \multicolumn{9}{|c|}{ Number of pollen grains with... } & \multirow{2}{*}{$\begin{array}{c}\text { Average } \\
\text { chromo- } \\
\text { some } \\
\text { number }\end{array}$} \\
\hline & & $n=8$ & $n=9$ & $n=10$ & $n=1$ & $1 n=12$ & $n=13$ & $n=14$ & $n=15$ & $n=16$ & \\
\hline $0-5$ & 3.86 & 3 & 6 & 7 & 3 & 14 & 5 & 0 & 0 & 0 & $10 \cdot 89$ \\
\hline $6-10$ & $8 \cdot 10$ & 6 & 10 & 9 & 16 & 18 & 9 & 9 & 0 & 0 & $11 \cdot 20$ \\
\hline $11-15$ & 13.06 & 7 & 12 & 17 & 19 & 24 & 11 & 5 & 7 & 0 & $11 \cdot 26$ \\
\hline $16-20$ & $18 \cdot 44$ & 7 & 8 & 14 & 23 & 22 & 21 & 10 & 3 & 0 & $11 \cdot 50$ \\
\hline $21-25$ & $23 \cdot 19$ & 8 & 10 & 20 & 32 & 32 & 23 & 8 & 8 & 0 & 11.49 \\
\hline $26-30$ & $28 \cdot 22$ & 9 & 9 & 18 & 28 & 38 & 20 & 11 & 1 & 1 & 11.42 \\
\hline $31-35$ & $32 \cdot 64$ & 2 & 8 & 24 & 25 & 31 & 12 & 4 & 0 & 0 & $11 \cdot 19$ \\
\hline $36-40$ & $38 \cdot 38$ & 1 & 10 & 17 & 31 & 18 & 10 & 10 & 2 & 1 & $11 \cdot 41$ \\
\hline $41-45$ & $44 \cdot 81$ & 6 & 4 & 12 & 31 & 23 & 12 & 9 & 2 & 2 & 11.63 \\
\hline $46-50$ & $48 \cdot 04$ & 3 & 9 & 12 & 27 & 16 & 25 & 6 & 2 & 0 & 11.53 \\
\hline $51-55$ & 53.08 & 4 & 2 & 14 & 34 & 24 & 15 & 5 & 1 & 0 & 11.43 \\
\hline $56-60$ & $59 \cdot 20$ & 1 & 7 & 18 & 20 & 23 & 17 & 10 & 5 & 1 & 11.99 \\
\hline $61-65$ & $64 \cdot 36$ & 2 & 6 & 11 & 23 & 22 & 23 & 11 & 5 & 2 & 11.97 \\
\hline $66-70$ & 67.67 & 1 & 5 & 14 & 21 & 32 & 20 & 9 & 4 & 0 & $11 \cdot 83$ \\
\hline $71-75$ & 72.91 & 2 & 2 & 14 & 24 & 27 & 17 & 9 & 3 & 2 & $12 \cdot 04$ \\
\hline $76-80$ & $78 \cdot 67$ & 0 & 6 & 20 & 24 & 15 & 12 & 16 & 6 & 1 & $11 \cdot 84$ \\
\hline $81-85$ & $83 \cdot 14$ & 2 & 1 & 15 & 25 . & 29 & 17 & 6 & 5 & 0 & 11.78 \\
\hline $86-90$ & $88 \cdot 37$ & 1 & 7 & 15 & 18 & 27 & 16 & 10 & 5 & 1 & 11.68 \\
\hline $91-95$ & $93 \cdot 16$ & 0 & 0 & 3 & 19 & 14 & 8 & 7 & 10 & 0 & $12 \cdot 44$ \\
\hline \multicolumn{2}{|c|}{ Totals } & 65 & 122 & 274 & 443 & 449 & 293 & 155 & 69 & 11 & \\
\hline
\end{tabular}




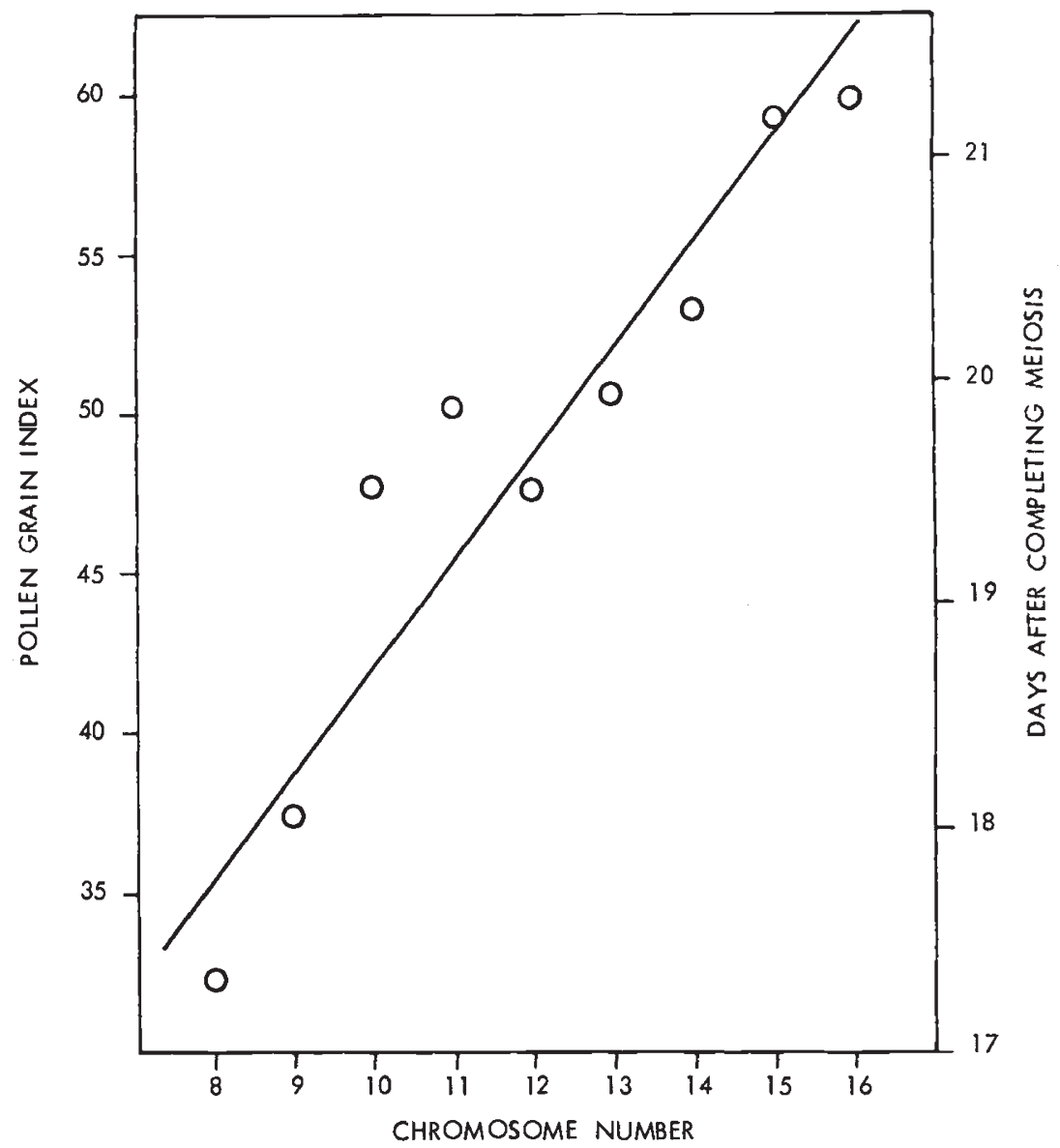

FIG. 1.-The average developmental "age", expressed as a pollen grain index at left and in days subsequent to meiosis at right, at which the nuclei of pollen grains with different chromosome numbers in triploid hyacinth reach metaphase of mitosis.

time at which pollen grains with different chromosome numbers are at metaphase of the first pollen grain mitosis. There is a positive and significant regression $(P=<0.01)$. The higher the chromosome number the longer the time to reach metaphase. Chromosome number is, of course, correlated with nuclear DNA amount and we may assume consequently that the duration of that part of the cell cycle from tetrad formation to metaphase is proportional to the DNA amount.

\section{(a) Control by chromosome number or DNA amount?}

It is a reasonable assumption but, after all, an assumption only that the control over the duration of the mitotic cycle is dependent upon the DNA amount as reflected by the chromosome number, rather than dependent upon the chromosome number per se. To distinguish between the two possibilities we have classified the pollen grains into five classes according 


\section{TABLE 2}

The DNA amounts (in picograms), chromosome numbers and complements of pollen grains at metaphase during the early (P.G.I. O-30), mid-period (P.G.I. 31-60) and late (P.G.I. 60-100) phases of development of anthers in triploid hyacinths.

\begin{tabular}{cccccc} 
& & & \multicolumn{3}{c}{ Numbers dividing } \\
\cline { 3 - 6 } DNA amount & Chromosome Chromosome & Early & Mid & Late \\
number & complement & (P.G.I. 0-30) & (P.G.I. 31-60) & (P.G.I. 61-95) \\
$28 \cdot 11$ & 10 & $4 L+3 M+3 S$ & 5 & 5 & 5 \\
$29 \cdot 00$ & 9 & $5 L+2 M+2 S$ & 26 & 16 & 19 \\
$30 \cdot 32$ & 10 & $5 L+2 M+3 S$ & 8 & 9 & 9 \\
$31 \cdot 18$ & 10 & $5 L+3 M+2 S$ & 15 & 32 & 22 \\
$32 \cdot 51$ & 11 & $5 L+3 M+3 S$ & 12 & 16 & 21 \\
$33 \cdot 28$ & 11 & $5 L+4 M+2 S$ & 6 & 13 & 6 \\
$33 \cdot 40$ & 10 & $6 L+2 M+2 S$ & 12 & 30 & 39 \\
$34 \cdot 69$ & 12 & $5 L+4 M+3 S$ & 9 & 8 & 9 \\
$34 \cdot 71$ & 11 & $6 L+2 M+3 S$ & 9 & 23 & 18 \\
$35 \cdot 58$ & 11 & $6 L+3 M+2 S$ & 20 & 52 & 48 \\
$39 \cdot 09$ & 13 & $6 L+4 M+3 S$ & 7 & 15 & 13 \\
$39 \cdot 11$ & 12 & $7 L+2 M+3 S$ & 5 & 11 & 21 \\
39.98 & 12 & $7 L+3 M+2 S$ & 15 & 21 & 28
\end{tabular}

to the DNA amount (table 2). Each DNA class in the table contains aneuploids with different chromosome numbers or different combinations of $L, M$, and $S$. We can now test whether the difference in chromosome number or combination within classes affects the duration of the mitotic cycle. A heterogeneity $\chi^{2}$ test shows that neither the chromosome number nor the combination of chromosomes within classes affects the time at which the grains reach metaphase viz. at low, medium or high P.G.I.'s $\left(\chi^{2}=4.4\right.$ for 16 degrees of freedom). The heterogeneity between DNA classes is, as expected, significant $\left(\chi^{2}=21.71\right.$, for 8 degrees of freedom). We may conclude with confidence therefore that it is indeed the DNA amount which determines the duration of the mitotic cycle and that the correlation between chromosome number and cell cycle duration in fig. 1 is an indirect result of the variation in DNA amount. At the same time the chromosome number is, in general, an useful and convenient reflection of the DNA variation and we have made use of chromosome number for further comparisons in both hyacinth and Scilla.

\section{(ii) Cell size}

Cell size, as we have said, is generally positively correlated with nuclear DNA amount. We should expect therefore to find grains with high chromosome numbers to be larger. Fig. 2 confirms that this is indeed the case. The regression is significant at the one per cent level. It will be recalled that with increase in chromosome number the longer is the duration of the mitotic cycle, including presumably that phase of the cycle devoted to the synthesis and assembly of proteins and other cell constituents i.e., to growth. It is tempting to explain the increase in cell size with increasing chromosome number on the basis that the growth phase is extended. While this may well be a causal factor we shall see later that it is unlikely to be the only factor affecting the size of pollen grains. 


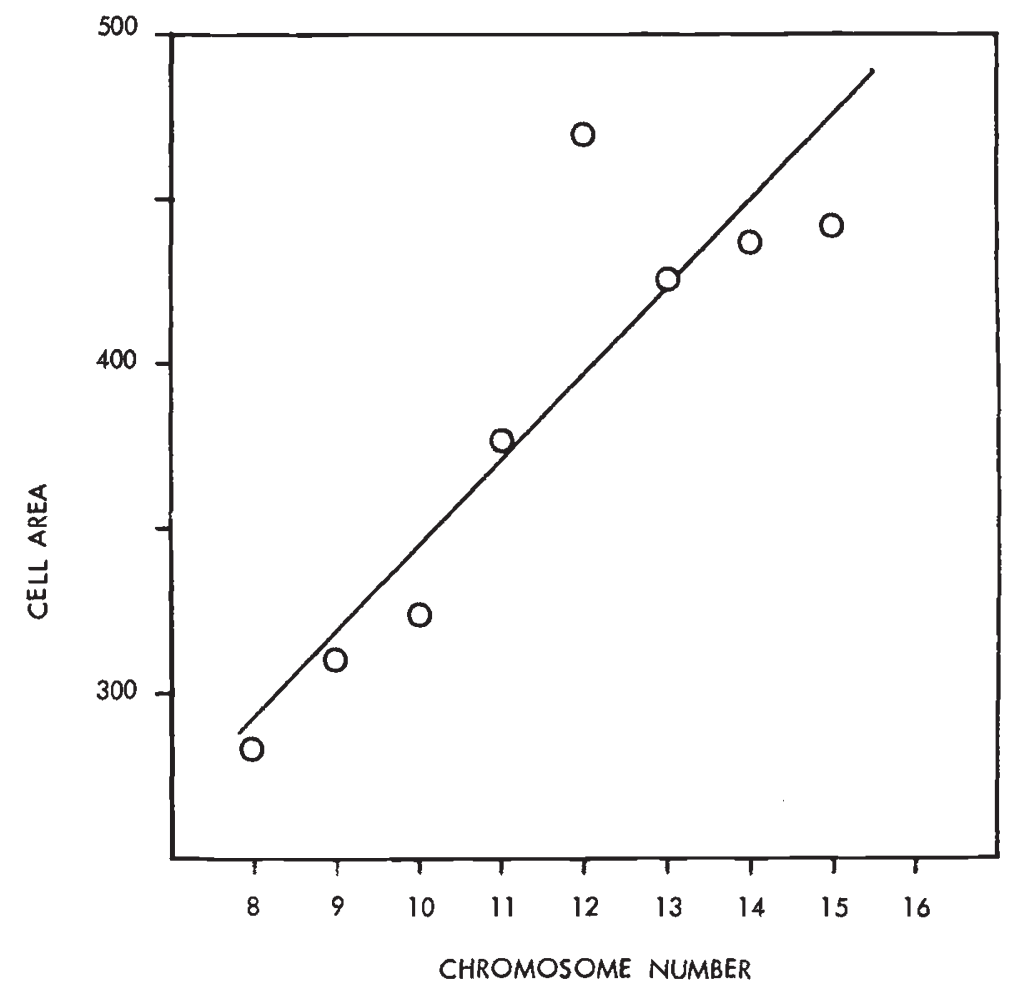

FIG. 2.-The mean areas (in microns ${ }^{2}$ ) of pollen grains in triploid hyacinth plotted against chromosome number. The area measurements derive from 100 pollen grains from a random sample of anthers. We have left out the areas for grains with 16 chromosomes. The sample was too small.

\section{(iii) Chromosome length}

There are good grounds for expecting that change in the duration of the mitotic cycle will affect the chromosome length at metaphase. As intimated above change in the duration of the total cycle is generally accompanied by change in all component phases of the cycle including the phase taken up by the division of the chromosomes (e.g., Evans et al., 1972). Given that the duration of prophase is extended with increase in the duration of the total cycle we should expect the coiling and contraction of the chromosomes to be that much greater, the chromosomes, consequently, that much shorter at metaphase. Our measurements showed that chromosome lengths in pollen grains reaching metaphase late (in anthers with a P.G.I. of 70 and above) are significantly shorter than in grains reaching metaphase early (in anthers with a P.G.I. of below 30). For example, the average length of the four long chromosomes decreases from 21.5 microns at the low P.G.I. to 17.3 microns at the high P.G.I. The difference was highly significant $(P=<0 \cdot 01)$. We have established earlier that pollen grains with high chromosome numbers reach metaphase, on average, later than those with low numbers. For this reason the pollen 
grains with high chromosome numbers have, on average, shorter chromosomes at metaphase. It is noteworthy that there is no variation in chromosome length between grains with different chromosome numbers from anthers with the same P.G.I. confirming that it is the cycle time and not the chromosome number as such which is the determinant.

There are observations of many years standing to the effect that the chromosomes of polyploid species at metaphase of mitosis are shorter than those of their diploid ancestors (e.g., Darlington, 1937). In general the duration of mitotic cycles in polyploids is longer than in diploids. In the light of our present observations these two properties are evidently directly and causally related.

\section{(iv) Is Hyacinth a special case?}

Among Flowering Plant species Hyacinthus orientalis is exceptional in its tolerance of aneuploidy (Darlington, Hair and Hurcombe, 1951). Gametes with chromosome numbers ranging from the haploid 8 to the diploid 16 are both viable and effective. Zygotes with chromosome numbers ranging from the diploid 16 to the tetraploid 32 are, similarly, viable and normal in growth and development as is reflected by the remarkable range of chromosome numbers among horticultural varieties. Are the nucleotypic effects in hyacinth upon the mitotic cycles, upon cell size and upon chromosome size pronounced and predominant by virtue of the absence of the confounding effects of genic imbalance of the kind manifested by aneuploid genotypes of other species of higher plants? According to Darlington (1937) a consequence of genic imbalance will be to impede and arrest the development of aneuploid grains. The following results from Scilla sibirica allow us to test such conclusions, to compare and contrast the effects of genotype and nucleotype and of this interaction.

\section{Scilla}

\section{(i) Cell cycle}

In table 3 and fig. 3 are the average "times" at which pollen grains with different chromosome numbers reach the first pollen grain metaphase. It will be observed that, as in hyacinth, the grains reaching metaphase earliest have fewest chromosomes. Thereafter, however, the graph departs very markedly from the hyacinth graph. Grains with from 7 to 12 chromosomes reach metaphase at much the same time.

The distinction between hyacinth and Scilla is especially clear in fig. 4, where we have plotted the average chromosome number of pollen grains at metaphase at different P.G.I.'s. In hyacinth the number increases steadily with increase in P.G.I. In Scilla the average number increases up to a P.G.I. of about 30 . Thereafter it remains constant. We interpret this as follows. The haploid grains with 6 chromosomes divide early (cf. fig. 3). The diploids with 12 divide late by virtue of the higher DNA content. The aneuploids are delayed such that they divide at the same time as the diploid. A genic effect in the form of imbalance is superimposed upon that of the nucleotype. 
TABLE 3

The distribution at metaphase of pollen grains in triploid Scilla with different chromosome numbers at different stages of anther development. Metaphase data are from counts in 2123 grains. P.G.I. values from roughly 10,000 grains.

\begin{tabular}{|c|c|c|c|c|c|c|c|c|c|}
\hline \multirow{2}{*}{$\begin{array}{l}\text { P.G.I. } \\
\text { range }\end{array}$} & \multirow{2}{*}{$\begin{array}{c}\text { Average } \\
\text { P.G.I. }\end{array}$} & \multicolumn{7}{|c|}{ Number of pollen grains with... } & \multirow{2}{*}{$\begin{array}{c}\text { Average } \\
\text { chromo } \\
\text { some } \\
\text { number }\end{array}$} \\
\hline & & $n=6$ & $n=7$ & $n=8$ & $n=9$ & $n=10$ & $n=11$ & $n=12$ & \\
\hline $0-5$ & $4 \cdot 13$ & 3 & 18 & 24 & 13 & 13 & 1 & 0 & $8 \cdot 25$ \\
\hline $6-10$ & $8 \cdot 27$ & 20 & 46 & 60 & 56 & 33 & 15 & 1 & $8 \cdot 36$ \\
\hline $11-15$ & 12.97 & 6 & 10 & 36 & 24 & 16 & 5 & 1 & $8 \cdot 54$ \\
\hline $16-20$ & $18 \cdot 70$ & 0 & 5 & 8 & 8 & 10 & 5 & 0 & $9 \cdot 05$ \\
\hline $21-25$ & $24 \cdot 10$ & 2 & 7 & 16 & 19 & 13 & 9 & 0 & 8.92 \\
\hline $26-30$ & 26.97 & 1 & 12 & 34 & 47 & 34 & 11 & 2 & $9 \cdot 00$ \\
\hline $31-35$ & 32.92 & 4 & 17 & 43 & 73 & 44 & 18 & 1 & 8.97 \\
\hline $36-40$ & 37.75 & 2 & 8 & 19 & 25 & 24 & 9 & 0 & $9 \cdot 01$ \\
\hline $41-45$ & $42 \cdot 84$ & 1 & 6 & 20 & 27 & 31 & 13 & 0 & $9 \cdot 22$ \\
\hline $46-50$ & $46 \cdot 11$ & 2 & 16 & 40 & 49 & 28 & 14 & 0 & 8.85 \\
\hline $51-55$ & $53 \cdot 15$ & 0 & 14 & 36 & 57 & 35 & 5 & 1 & $8 \cdot 81$ \\
\hline $56-60$ & 59.05 & 1 & 6 & 22 & 25 & 23 & 9 & 0 & 9.04 \\
\hline $61-65$ & 63.67 & 0 & 10 & 35 & 57 & 38 & 8 & 0 & 8.99 \\
\hline $66-70$ & $69 \cdot 00$ & 0 & 8 & 19 & 18 & 18 & 3 & 0 & $8 \cdot 83$ \\
\hline $71-75$ & 72.98 & 0 & 11 & 29 & 32 & 27 & 4 & 0 & 8.84 \\
\hline $76-80$ & $78 \cdot 50$ & 1 & 7 & 34 & 33 & 20 & 7 & 1 & 8.86 \\
\hline $81-85$ & 83.81 & 1 & 14 & 35 & 45 & 31 & 10 & 3 & 8.96 \\
\hline $86-90$ & 88.53 & 0 & 7 & 31 & 49 & 19 & 5 & 0 & $8 \cdot 85$ \\
\hline $91-95$ & $94 \cdot 27$ & 0 & 6 & 11 & 18 & 4 & 2 & 0 & 8.63 \\
\hline \multicolumn{2}{|c|}{ Totals } & 44 & 228 & 552 & 675 & 461 & 153 & 10 & \\
\hline
\end{tabular}

\section{(ii) Cell size}

In hyacinth the pollen grains with most chromosomes and, hence, highest DNA amounts took longer to reach metaphase of the first pollen mitosis. We surmised that the cells with the longer cycles would have "more time to grow" with the result that they would be, as observed, bigger cells. In Scilla, apart from haploid grains, we found that cells with different chromosome numbers divided at much the same time. If size were dependent only upon the duration of the mitotic cycle, as we might have supposed from the hyacinth results, our expectation in Scilla would be that grains reaching metaphase at about the same time, namely those with from 7 to 12 chromosomes, would be of the same size. They are not (fig. 5). There is, as in hyacinth, a clear and highly significant linear correlation between chromosome number and cell size at metaphase. Evidently cell size in Scilla is, at least partly, independent of the duration of the cell cycles. In the light of this evidence we must face the possibility that in hyacinth, also, the relationship between the duration of the mitotic cycle and cell size is not entirely of a causal nature. An alternative possibility is that the dosage of genes concerned with growth of the pollen grain, and the magnitude of their effects, increase with increasing chromosome number. There are other possibilities but, to date, conjectural rather than established. What is clear, however, is that pollen size is in both species closely dependent upon chromosome number and mass. 


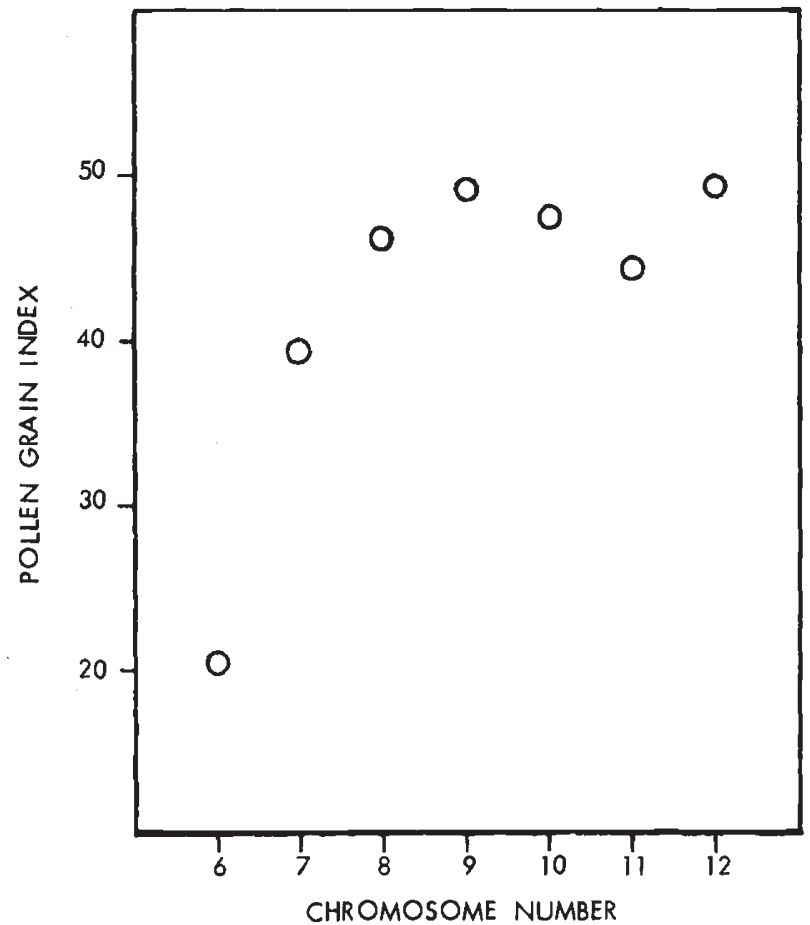

FIG. 3.-The average developmental age, expressed as a pollen grain index, at which the nuclei of pollen grains with different chromosome numbers in triploid Scilla reach metaphase of mitosis.

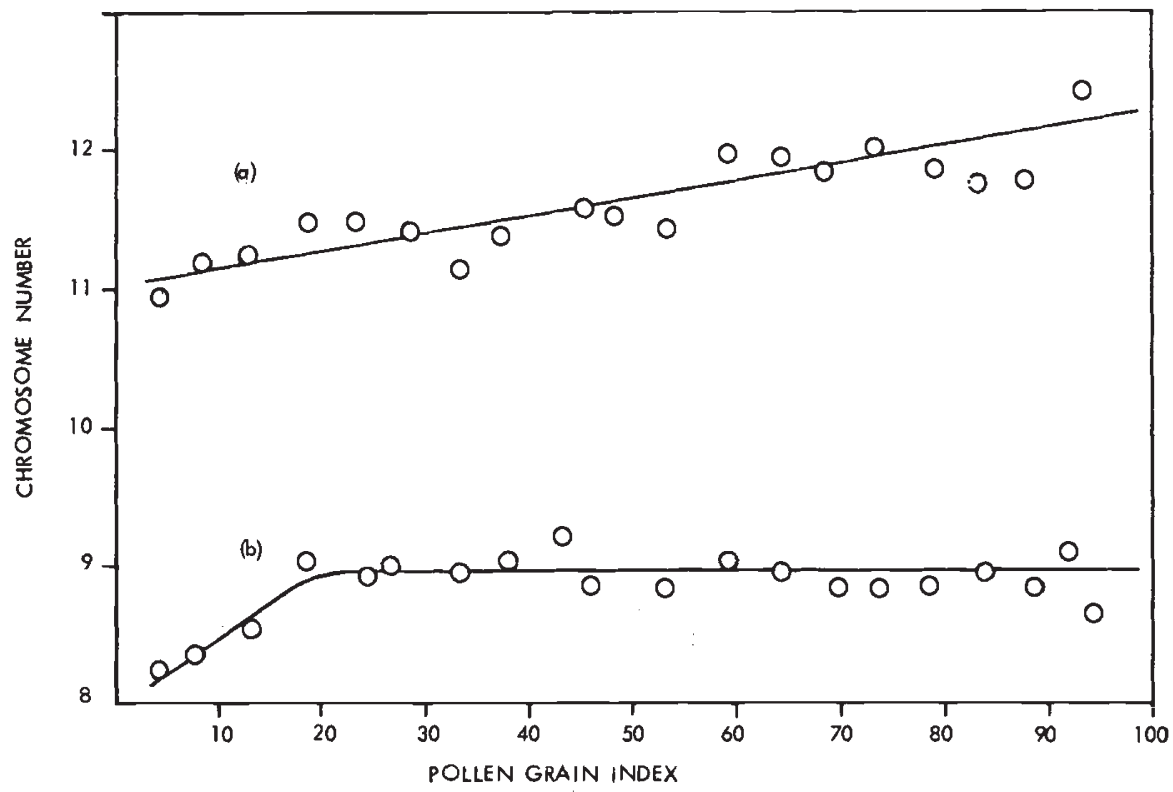

FIG. 4.-The mean chromosome number of pollen grains reaching metaphase in anthers of different developmental age in triploids of hyacinth (a) and Scilla (b). 


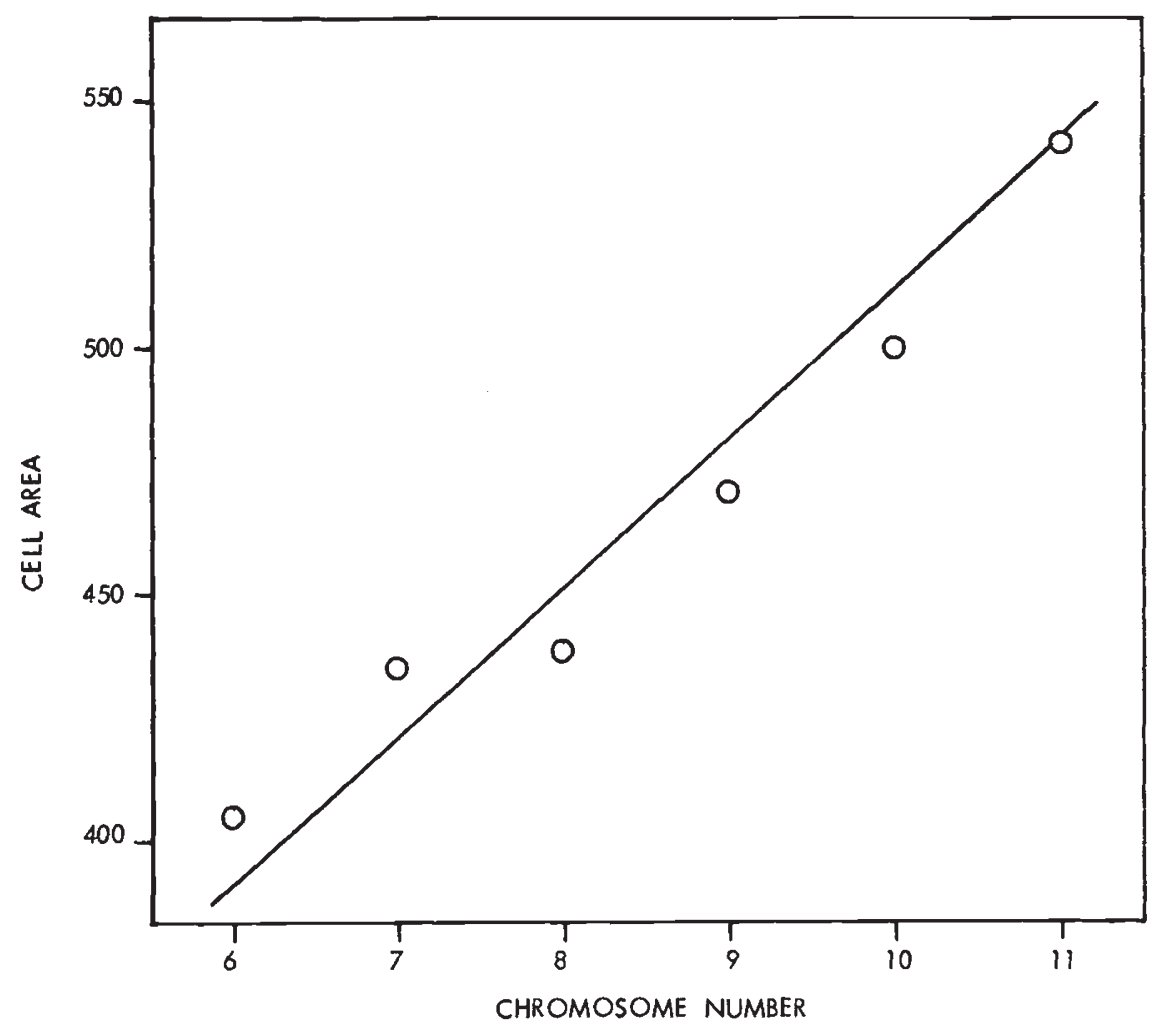

FIG. 5.-The mean areas (in microns ${ }^{2}$ ) of pollen grains in triploid Scilla plotted against chromosome number. The area measurements derive from 100 pollen grains from a random sample of anthers. The sample of grains with 12 chromosomes measured was too small for inclusion.

\section{Conclusions}

In hyacinth pollen grains the effects of the nucleotype, as reflected by the nuclear DNA amount, upon the duration of the mitotic cycle, the cell size and the chromosome length at metaphase are clear and unambiguous. Considered by themselves they are readily explained as a chain reaction; the more DNA the longer the period for DNA synthesis and for other components of the mitotic cycle; the longer the cycle the longer the growth period and, consequently, the larger the cells; the longer the prophase the greater the contraction, the shorter the chromosomes at metaphase. And vice versa. The Scilla results tell us that while these relationships are valid they are neither absolute nor exclusive. (1) In contrast to hyacinth the evidence from Scilla indicates that aneuploidy disrupts the relation between nuclear DNA amount and the duration of the mitotic cycle, that the effects of genotype, in the form of genic imbalance, are superimposed upon those of the nucleotype. (2) The cell size in Scilla pollen grains correlates closely, as in hyacinth, with chromosome number and DNA amount. But while, the larger cell size of pollen grains with high chromosome numbers in hyacinth was interpretable on the grounds of the longer duration of their 
mitotic cycles the same could not apply in Scilla, where the duration of the mitotic cycles was not directly proportional to the chromosome number. Nucleotypic effects on certain aspects of the cellular phenotype are certainly widespread and often predominant. Our investigation in pollen grains shows, as indeed we might have expected, how these effects may be confounded and even overridden by the genotype. In more general terms it appears that the nucleotype imposes certain regulations and constraints upon cell growth and development but regulations and constraints which are subject to modification and elaboration by the genotype.

\section{REFERENCES}

BENNETT, M. D. 1970. The duration of meiosis. Proc. Roy. Soc. B, 178, 277-299.

BENNETT, M. D. 1972. Nuclear DNA amounts and minimum generation time in herbaceous plants. Proc. Roy. Soc. B, 191, 109-135.

CAVALIER-SMITH. T. 1978. Nuclear volume control by nucleoskeletal DNA, selection for cell volume and cell growth rate, and the solution of the DNA $c$-value paradox. J. Cell Sci. 34, 247-278.

DARLINGTON, C. D. 1937. Recent Advances in Cytology. London: Churchill.

DARLINGTON, C. D., HAIR, J. B., AND HURCOMBE, R. (1951). The history of the garden hyacinths. Heredity, 5, 233-252.

EVANS. G. M., REES, H., SNELL, C. L.. AND SUN, S. (1972). The relationship between nuclear DNA amount and the duration of the mitotic cycle. In Chromosomes Today, vol. 3, Longman, London, pp. 24-31.

MARTIN. P. G. 1966. Variation in the amounts of nucleic acids in the cells of different species. Expl. Cell Res. 44, 84-90. 